properties of periodates are treated, and there follows what should have been a valuable account of the mech. anism of diol fission. Although much important information has been collected, this section is particularly spoiled by inaccuracies which destroy completely many of the points made. It is more than difficult, for example, to follow a discussion of the relative rates of oxidation of erythro- and threo-butane-2,3-diol when the formulae of the two compounds are interchanged; nor is it easy to understand why the compound now known as $1,4,5,6$ tetra-O-acetyl-myo-inositol should be resistant to oxidation-especially when it is described as 1,2,3,4-tctra. methyl-meso-inositol. No comment is provided.

There follows a chapter on "Anomalous Periodate Oxidations" (which are "non-Malapradian" rather than anomalous) which deals disproportionately briefly with oxidations of, for example, sulphur-containing compounds, phenols and amino-acids. The book therefore treats the periodate oxidation of carbohydrate compounds almost exclusively. Chapter five gives an account of the use of periodate reactions in carbohydrate stuctural analysis without illustrating the full power of the technique in the elucidation of structures of complex polysaccharides.

A quarter of the book is appropriately devoted to the purely analytical aspects of the subject, and although valuable information and experimental detail are catalogued, again a more critical and comparative appraisal would have been welcome. Anybody applying the procedure on p. 124 (for the determination of the reduction of the periodate ion) in oxidations of most carbohydrate compounds can expect to be disillusioned: the technique was developed specifically for use with highly susceptible ribofuranosyl compounds. Finally, a short section is devoted to the use of periodate in synthetic chemistry.

No doubt the book will be a useful source of information to research workers in carbohydrate and analytical chemistry as intended by the author, but it lacks the authority and comprehensiveness for recommendation for this purpose, and on account of the many inaccuracies it contains, it is not wholly suitable for advanced undergraduate and postgraduate students--the other groups for whom it was written.

R. J. FERRIER

\section{THERMOCHEMICAL JOURNAL}

\section{Thermochemica Acta}

Vol. 1, No. 1. Bimonthly. (Elsevier: Amsterdam, March 1970.) $\$ 22.50$ per vol.

IN recent years there has been a marked increase in the number of research papers published in the general area involving measurements of thermochemical phenomena. This may result partly from the provision of apparatus for the precise and sensitive measurement of small temperature changes, or perhaps more from a realization by researchers in various fields that so much information may be gained by studying thermal effects. In many instances this information is more detailed in aspects which are scarcely shown up by measurements of electrochemical, spectrochemical or nuclear signals. Perhaps the realization of potential and availability of equipment are jointly responsible for the increase in activity in this subject.

It is the contention of the publishers of this new journal and of the editor-in-chief, Professor W. W. Wendlandt, of the University of Houston, that the information is being too widely dispersed throughout the literature and that the time has come to have a specialized journal. It is intended that this new journal should deal primarily with papers on the application of calorimetric and thermometric techniques to research problems in inorganic, organic, polymer, physical, analytical and bio-chemistry.

The first issue carries 105 pages of editorial matter and is made up of twelve papers and one note from sources in the United States and Canada (with one joint US/UK paper). The subject matter of these papers ranges from thermal decomposition studies, thermodynamic kinetics, to thermogravimetric analysis, and the like.

It seems probable that the journal will be of very considerable value to those who are interested in thermochemical phenomena and that it will provide a suitable forum for papers in the area which might not fit too easily into journals of physical or analytical chemistry.

Much as one deplores the proliferation of more and more journals it does seem that there is more justification for this one than for most. It will, however, be interesting to see if it can maintain coherence in the face of the many papers from very diverso laboratories, which are quite likely to pour into it.

T. S. WEST

\section{GUIDES FOR AUTHORS}

Maps for Books and Theses

By A. G. Hodgkiss. Pp. $267+8$ platos. $55 s$.

Photography for Books and Reports

By Brian Bracegirdle. Pp. $247+50$ plates. $70 s$.

Non-Fiction

A Guide to Writing and Publishing. By David St. John Thomas. Pp. 192. 35s.

(David and Charles: Newton Abbot, April 1970.)

AurHors who are apprehensively awaiting publication of their first books might wish that they had been able to browse through these books before commencing writing. All three are aimed at the specialist, scientific or otherwise, who is writing a book on his subject, but has little previous experience of such writing. All are competently written and well produced. The books on map making and on photography, however, leave an impression that authors who require these techniques would be best advised to employ a professional cartographer or photographer. These two books are intended to be of restricted scope, and fall neatly between two stools; the level of competence which is clearly required to enable the uninitiated to use these techniques would seem unlikely to be attained by reading books, no matter how well written; and the professional, of course, has little need of such advice.

Non-Fiction : a Guide to Writing and Publishing is, however, of rather more general interest. As with more special. ized books, a fair proportion of its content is confined to stating what must be obvious even to the innocent writing his first book. And some of the book is of only limited interest to the scientist; for example, discussion of the publishers which an author should approach and of the form of contract he should seek must be in such vague terms as to be of little practical use. For the scientist, at any rate, these decisions must depend so very largely upon his particular field of interest that general advice is not very helpful.

But much of this book is of real value, even to those who already have some experience of writing. Examination of articles in some journals, for instance, shows that many authors-let alone of books-could benefit from the chapters on the presentation of manuscripts. The book contains a wealth of interesting information on the techniques of publishing and the stages through which a manuscript must pass, and this must interest any author. And on one count, at least, the book must be strongly recommended; its cost could easily be recouped by ref. erence to the excellent section on the taxation of earnings from writing. On balance, Non-Fiction is a book to be recommended, not only to prospective authors, but also to those who are not yet so well established that they can afford to ignore its recommendations.

Benjamin M. Lewin 